
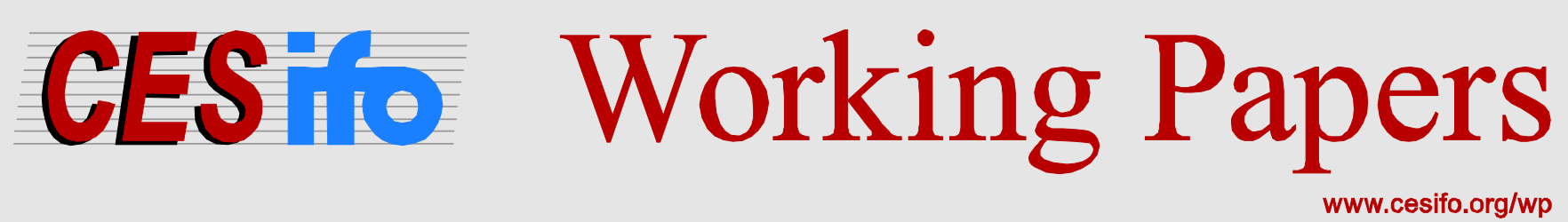

\title{
Offshoring and Volatility of Demand
}

\author{
Sebastian Benz \\ Wilhelm Kohler \\ Erdal Yalcin
}

\author{
CESIFO WORKING PAPER NO. 5970 \\ Category 8: Trade Policy \\ JUNE 2016
}
An electronic version of the paper may be downloaded
- from the SSRN website: Www.SSRN.com
- from the RePEc website: Www.RePEc.org
- from the CESifo website: www.CESifo-group.org/wp




\title{
Offshoring and Volatility of Demand
}

\begin{abstract}
In this paper we explore the role that demand uncertainty plays for the offshoring decision, and the role that offshoring plays for domestic volatility of employment. Offshoring is modeled as in Antràs \& Helpman (2004), but we assume complete contracts. Firms are heterogeneous as in Melitz (2003). Uncertainty arises through recurring firm-specific shocks to demand. The presence of a cost of firing or hiring as in Bagliano \& Bertola (2004) generates an intertemporal element to a firm's employment decision in its domestic and offshore production. In this environment, offshoring is driven by differential labor market exibility as well as by wage differences. Our most important results are: 1) If the foreign labor market features a high exibility, measured relative to its wage rate, compared to the domestic labor market, then higher uncertainty has a pro-offshoring effect. And 2), under this same condition, offshoring increases volatility in domestic employment of offshoring firms and the volatility of offshore employment of these same firms is larger than volatility of domestic employment.
\end{abstract}

JEL-Codes: F100, F120, F160.

Keywords: offshoring, volatility, labor market flexibility.

\author{
Sebastian Benz \\ OECD \\ Paris / France \\ sebastian.benz@oecd.org
}

\author{
Wilhelm Kohler \\ University of Tübingen \\ Tübingen / Germany \\ wilhelm.kohler@uni-tuebingen.de
}

\author{
Erdal Yalcin \\ Ifo Institute - Leibniz Institute for \\ Economic Research at the University of Munich \\ Poschingerstrasse 5 \\ Germany-81679 Munich \\ yalcin@ifo.de
}

May 2016

A preliminary version of this paper was presented at the CESifo Venice Summer Institute Workshop entitled "New Developments in Global Sourcing", held at Venice International University, San Servolo, July 22-23 2015. We have greatly benefitted from comments by workshop participants. We are grateful for financial support received from Deutsche Forschungsgemeinschaft (DFG) under grant no. KO 1393/2-1 | YA 329/1-1/ AOBJ: 599001. All information and views expressed are sole responsibility of the authors. The content of this paper does not necessarily reect the opinion of the OECD Secretariat or any OECD member country. 


\section{Introduction}

In the economics literature, offshoring is largely portrayed as a cost-driven phenomenon. According to this view, technology-induced reductions in the costs of transport and communication facilitate fragmentation of production processes into multiple stages that may be separated in space, albeit at a "separation cost". Comparing his separation cost with the cost advantage from moving different inputs to locations with different input prices determines a cost-minimizing location pattern for the entire supply chain. Typically, different parts of the supply chain will be located in different countries, which in turn gives rise to offshoring. The most well known model for this view of offshoring is Grossman \& Rossi-Hansberg (2008).

Although this view of cost-driven offshoring is no doubt an important part of the story, the business literature as well as practitioners have always emphasized that in practice the offshoring calculus must go beyond narrow cost considerations. However, economists have been slow to adopt additional elements of "increased realism" in their formal models of offshoring. ${ }^{1}$ In this paper, we add realism by looking at uncertainty. In particular, we investigate the role that demand uncertainty plays for the offshoring decision, and the role that offshoring plays for domestic volatility of employment, given this uncertainty in demand. ${ }^{2}$

More specifically, we analyze the problem that producers face when confronted with demand uncertainty, if adjusting to different states of demand is costly. In our case the cost of adjustment derives from firing as well as hiring cost for workers. The obvious interpretation of this set up is the presence of labor market regulation, although our model allows for a more general interpretation that also includes real resource use caused by stock adjustments of employment. In such an environment, if the domestic and foreign economies differ in their labor market institutions that influence hiring and firing costs,

\footnotetext{
${ }^{1}$ See for instance Roza et al. (2011) for a comprehensive empirical analysis of various drivers of offshoring.

${ }^{2}$ Throughout this paper, the two terms uncertainty and risk are used interchangeably. The Knightian distinction between risk and uncertainty is irrelevant for the present purpose.
} 
offshoring may - in and of itself - be an important element of a firm's optimal strategy to deal with demand uncertainty. We argue that this is an important aspect in a more comprehensive view of offshoring. ${ }^{3}$ To the best of our knowledge, there is no formal model of offshoring that incorporates this aspect of costly adjustment in a world of uncertainty. We develop a theoretical approach that combines elements of the canonical model of global sourcing introduced by Antràs \& Helpman (2004) with a dynamic treatment of hiring and firing cost as proposed by Bagliano \& Bertola (2004), in order to shed light on costly adjustment in an uncertain environment as an important driver of the offshoring decision.

If the ease of adjustment to changes in demand is an important driver behind offshoring, as we argue in this paper, then an obvious question to ask is how globalization, in our case an increase in openness to offshoring, affects domestic volatility. Intuitively, since offshoring shifts part of the adjustment to the foreign economy, volatility is "exported" to the foreign economy. However, this need not reduce aggregate volatility in the domestic economy, since offshoring implies reallocation of domestic labor to other production stages, or other products, which may be subject to the same, or even a higher demand uncertainty. Indeed, our analysis shows that under plausible conditions aggregate volatility is increased. If offshoring responds to a lower cost of adjustment in the foreign economy, then the fluctuations in offshore production of inputs will be larger than would be observed if those inputs had been procured domestically, given the same underlying fluctuation in demand. And if the inputs produced domestically and offshore are complements in that a larger quantity of one increases the marginal productivity of the other, then offshoring to a more flexible economy fires back in terms of a larger fluctuation also in the domestic input. In this case, offshoring causes the domestic economy

\footnotetext{
${ }^{3}$ The motivation for our analysis is nicely reflected in the following quote from the business literature: "One obvious strategy for many global companies is to go where the talent is abundant or where the costs are low, as many companies have done in the past three decades. This means taking advantage of the most cost-effective sources of talent and other inputs wherever they exist. Such a strategy will require significantly greater flexibility in coming years, since global supply chains are dynamic and the trade-offs in choosing the best locations are becoming more complex. Simple labor cost arbitrage may not be sufficient. ... Companies are also thinking about how to make supply chains more agile and flexible to achieve greater speed and responsiveness to changes in consumer tastes and demand." See Manyika et al. (2012).
} 
to "import" higher volatility from the more flexible foreign economy, even though the underlying shocks are the same for the adjustment of both, the domestic and the offshore input. Therefore, under certain conditions offshoring firms will exhibit a higher revenue and employment volatility than firms that rely on domestic sourcing. We shall explore what this implies for aggregate employment volatility. ${ }^{4}$

We employ a very stylized model of offshoring which allows us to add the key novel elements of uncertainty and costly adjustment with a minimum amount of complexity. In a nutshell, our model runs as follows. There are two economies, called North and South, with given endowments of a single factor, labor, which is mobile across sectors. There are $J+1$ sectors, sector 1 being a "numéraire sector" that ties down the wage in each country. Each of the $J$ manufacturing sectors features product differentiation, based on CES-preferences as in Dixit \& Stiglitz (1977). Importantly, these preferences feature parametric uncertainty which translates into demand uncertainty for firms. There is monopolistic competition on goods markets, with firms differing in their productivity levels, as in Melitz (2003). The size of each sector is determined by the condition that firm-values, based on expected productivity as well as on expected demand, are equal to a fixed entry cost. Assuming a large number of manufacturing sectors allows us to model uncertainty in a way that does not affect the aggregate size of manufacturing in the economy. We thus focus on uncertainty-driven adjustment of employment within the manufacturing sector of the economy. Production of manufacturing goods is governed by a Cobb-Douglas function in two inputs, an input that needs to be provided in the

\footnotetext{
${ }^{4}$ Whether economic globalization tends to increase or decrease individual risk and aggregate volatility is a "classic" concern for policy makers as well as individuals. In a famous paper, Rodrik (1998) has argued that the positive cross-country correlation between trade-openness and the size of the government is partly explained by higher trade openness causing higher individual labor market risk and, thus, a bigger scope for beneficial government intervention, given the well known failures of insurance markets with respect to labor market risk. However, in view of our own results, we caution against interpreting any increase in volatility as an unwelcome event. While it is true that repeated adjustment to shocks does cause adjustment cost on the part of individual households (either as workers or owners of firms), some adjustment will typically be beneficial; see Haltiwanger (2011). This holds true even if individuals are risk averse. In our model, we assume that individuals are risk-neutral, but we do take into account adjustment cost. If adjustment decisions are made taking into account undistorted adjustment cost, then the amount of adjustment, and hence the degree of volatility, should be considered optimal. To argue that an increase in volatility, say brought about by greater trade-openness, is a detrimental event is thus valid only in the sense of acknowledging that, contrary to the model assumption, individuals are risk-averse and cannot insure against the risk in question.
} 
North, and an input that may be provided in the North, or produced "offshore" in the South. This follows Antràs \& Helpman (2004), but to keep the analysis simple we assume complete contracts, whence the analysis is restricted to the location of sourcing (offshoring margin), leaving a treatment of the organizational form of sourcing (vertical integration versus outsourcing) to future research. Both types of inputs are produced with a constant labor productivity, and labor markets in both economies feature perfect competition.

The novel feature of the offshoring decision as modeled in this paper relates to a firm's adjustment of the employment level when it faces a change in in the state of demand: We assume that for each of the two inputs any change in employment levels that a firm may want to carry out in pursuit of profit maximization when facing a change in demand is subject to cost of hiring or firing, depending on the direction of this change. These costs are assumed to be the same for both types of inputs, but to be different in the South and in the North. We frame our analysis in terms of a more flexible labor market in the South, whence both hiring and firing costs are lower in the South than in the North. Following Bagliano \& Bertola (2004), we assume that firms always observe the present state of demand, but they face demand uncertainty for future periods. This makes the choice of employment levels a dynamic problem: Increasing employment if the present state of demand is high increases the cost of adjustment when the state of demand will be low in the future. In other words, present employment decisions affect adjustment costs in the future. As a result, an optimal employment path requires that expected future states of demand have an influence on employment levels chosen at the present. The hiring and firing cost thus determines the optimal response to changes in demand over time, which in turn determines the degree of employment volatility in the economy considered.

We use this model to contribute to the literature in two distinct ways. The first relates to the role that this type of uncertainty plays for offshoring. In the type of environment depicted by our model, the offshoring decision is governed, not just by a wage cost advantage in the South, but also by how the South compares to the North in terms of the hiring and firing cost. A wage advantage may be partly eroded by more 
costly adjustment, or it may be reinforced by less costly adjustment in the South. We explore this additional driver of offshoring, which has so far not been addressed in the literature. Broadly speaking, this literature falls into two classes of models differing by the type of margin considered. A large body of literature, sparked off by Antràs \& Helpman (2004), assumes firm heterogeneity and considers the extensive firm margin that separates firms choosing different locations or ownership structures or sourcing. A second class of models, pioneered by Grossman \& Rossi-Hansberg (2008), assumes homogeneous firms and focuses on the extensive task margin that separates the types of tasks that profit maximizing firms will source domestically and offshore, respectively. Our model squarely focuses on the extensive firm margin. ${ }^{5}$ Our second contribution to the literature relates to the role of globalization for volatility. There is a large body of literature in the spirit of Rodrik (1998) that asks whether greater trade openness exposes countries to greater risk. In our model, the underlying parametric demand uncertainty is independent of where the manufacturing input is sourced, so that globalization does not affect the degree of risk as such. But the extent to which this risk generates employment volatility does depend on offshoring, if the two countries feature differently flexible labor markets. It is this type of offshoring-volatility nexus that is at the heart of our paper.

Our analysis is closely related to three important recent papers. The first is by Anderson (2011) who proposes a continuum of goods version of the specific factors model, in order to analyze the effect of opennes to trade on individual income risk deriving from productivity shocks. In that model, much depends on the type of shock considered. If shocks are idiosyncratic to sectors, meaning that the home country becomes more or less productive in a certain sector, relative to other countries, then trade makes incomes of sector-specific factors more risky and incomes of the mobile factor less risky. ${ }^{6}$ Conversely, if shocks are aggregate in nature, meaning that the home country becomes more or less productive relative to other countries across the board of all sectors, then trade reduces

\footnotetext{
${ }^{5}$ Note again, however, that we do not address contractual incompleteness, which plays a large role in this literature. For recent surveys of this literature, see Antràs \& Yeaple (2014) and Antràs (2015).

${ }^{6}$ Sector-specificity implies that factors are allocated across sectors before the shock arises and cannot be reallocated afterwards.
} 
all income risk. These effects are driven by two margins of adjustment, the extensive margin where more sectors become exposed to trade (either through exports or through import competition), and the intensive margin where more trade takes place within sectors. Importantly, adjustment of employment levels for all inputs is assumed costless. Our model differs from Anderson (2011) in several ways. First, we look at input trade instead of final goods trade. Perhaps more importantly, we emphasize costly adjustment in employment, focusing on volatility of employment levels within sectors, rather than factor incomes under frictionless adjustment between sectors. And finally, our model features a single factor (labor) which is mobile across sectors (albeit subject to adjustment cost), whence the aforementioned distinction between sector-specific and mobile factor incomes does not arise. For the same reason, the distinction between idiosyncratic and aggregate shocks becomes irrelevant, although the shock considered is sector-specific.

Similar to our paper, Cuñat \& Melitz (2012) consider a single factor (labor only) economy and highlight a friction in the adjustment of employment levels in an environment characterized by uncertainty. They assume a continuum of final goods (industries), each produced with a CES-continuum of intermediate goods. There are two countries, one with a frictionless labor market, and one where employment levels in the production of intermediate goods must be chosen before productivity is known (based on expectations) and cannot be changed thereafter. Uncertainty applies to productivity levels, drawn from sector specific distribution functions that are common to both countries, but specific to industries. The variance of this distribution for a certain industry determines the postshock variance of productivity across different intermediate input producers within this industry. In the rigid economy, final goods producers cannot adjust to different productivity levels of intermediate input producers within industries, because these cannot adjust their employment levels. In the flexible economy adjustment is possible, which generates an absolute advantage in that it affords it a lower price of all final goods compared to the rigid economy. Importantly, however, this advantage is the larger, the larger the variance of productivity across different intermediate input producers. Hence, if final goods (industries) differ in terms of this variance (some industries being more volatile than others), 
then the cross-country difference in labor market flexibility gives rise to a distinct pattern of Ricardian comparative advantage. ${ }^{7}$ In the rigid economy, there will be zero volatility of employment levels across different intermediate goods producers within any final goods industry, whereas in the flexible economy this volatility is positive, determined by the variance of the underlying distribution function for productivities. More importantly, with trade this economy will be specialized in more volatile industries, whence trade in final goods increases the macro-volatility in the flexible economy, although it does not affect the underlying uncertainty as such. Moreover, intermediate input prices reflect the same productivity distribution across intermediate input producers, whereby this distribution is the same for both countries and remains unaltered by trade. Moreover, there is no income risk, since wage rates are determined prior to the productivity draw in a way that clears the labor market ex post. ${ }^{8}$ Our model is similar to Cuñat \& Melitz (2012) in that we also focus on adjustment frictions, but instead of ruling out adjustment altogether we assume that adjustment is costly. Also, we use a different notion of volatility. In their model, volatility relates to variations across producers of different intermediate inputs at any point in time. In our model, volatility relates to the extent of adjustment of any one producer across different states of demand evolving through time. An important further difference lies in the dynamic nature of the employment decision that derives from the type of adjustment cost considered, viz. hiring and firing cost. And finally, as with Anderson (2011), our model is different in that we focus on input trade rather than final goods trade.

The paper closest to ours is Bergin et al. (2011) which similarly focuses on offshoring and employment volatility. Like ours, their model has two sectors, a standard sector without fragmented production and offshoring, and a manufacturing sector that permits offshoring. Assuming two countries (home and foreign), the primary margin of adjustment in offshoring derives from a function of relative labor input coefficients for a continuum

\footnotetext{
${ }^{7}$ In Cuñat \& Melitz (2010), the authors present a general formulation of this type of theory of comparative advantage.

${ }^{8}$ Of course, the absolute advantage afforded by a flexible labor market is reflected in a higher wage in the flexible than in the rigid country.
} 
of manufacturing products, as in Dornbusch et al. (1977). Hence there is an extensive product margin of offshoring. Each country has preferences where a composite of the manufacturing good and the standardized home good is nested in Cobb-Douglas fashion with the foreign good. The standard good is thus differentiated by country of origin, the familiar Armington-assumption. Similar to our model, Bergin et al. (2011) consider a demand shock in terms of a parametric change in preferences; in their case the shock favors the manufacturing good (featuring multinational production) as well as the home country's standard good. The model can be solved in terms of how manufacturing employment in one country relative to the other responds to this demand shock, whereby the key channel of adjustment is the extensive goods margin of offshoring. This allows the authors to address what they call the "offshoring volatility puzzle" observed for US offshoring to Mexico: The maquiladora industries in Mexico exhibit larger employment volatility than the corresponding industries in the US; see Bergin et al. (2009). The puzzle is that this is true despite Mexico being a less flexible country than the US by usual measures of labor market flexibility. Bergin et al. (2011) demonstrate that in their model such an asymmetric volatility effect may derive from the aforementioned demand shock. The reason is that this shock works asymmetrically in the two countries: The home country gains manufacturing employment on account of larger demand for manufacturing goods while losing manufacturing employment due to a shift at the extensive margin of offshoring. In contrast, the foreign economy gains manufacturing employment on both accounts. In an environment of demand uncertainty, this generates more volatility in the foreign economy than in the home economy. Calibrating their model and simulating repeated i.i.d. demand shocks through time, they demonstrate that the simulated volatilities are close to the magnitudes observed in US and Mexican data. Our paper is different from Bergin et al. (2011) in that offshoring emerges at an extensive firm margin rather than a product margin. Moreover, our demand shocks apply to differentiated varieties within a sector (industry), rather than to an industry as a whole. Most importantly, in contrast to Bergin et al. (2011), we assume that adjustment of employment levels to such demand shocks is costly, such that the employment decision becomes a dynamic problem. 
As a result, offshoring is not only driven by a wage advantage of the foreign economy, but also by different adjustment costs in the two countries considered.

The rest of the paper is structured as follows. Section 2 presents the model, starting out with preferences and demand uncertainty, to be followed by a presentation of the dynamic employment decision that derives from this uncertainty as well as the offshoring decision by firms differing in their productivity. Section 3 turns to general equilibrium by focusing on the entry decision and on the trade balance condition. Section 4 derives propositions on how different labor market flexibility in the face of demand uncertainty affects the extensive margin of offshoring, and on how trade liberalization affects employment volatility through a change in this margin. Section 5 concludes the paper with a brief summary.

\section{Offshoring under demand uncertainty}

We assume a world economy composed of two countries, labeled North and South, each endowed with a given amount of a single type of labor. All worker-households in both countries have the same preferences over $J+1$ goods, whereby good 0 is a standardized good and each of the $J$ manufacturing goods is composed of differentiated varieties. By assumption, good 0 is produced in both countries, and the market for this good is perfectly competitive, whereas each of the manufacturing sectors, $j=1 \ldots J$, is governed by monopolistic competition. Each variety of a good is produced using two types of inputs. One of these inputs, called the "headquarter input", can be produced only in North. The second is called the "manufacturing component" and can be produced either in North or South. Both inputs are produced using only labor. Demand in the manufacturing sector is stochastic, switching between good and bad states, independently for each sector $j$. Employment adjustment to such changes in demand is subject to a hiring and a firing cost, respectively, whereby the two types of cost are symmetric. Importantly, however, this cost is higher in North than in South. Firms differ in terms of the productivity when 
assembling the two types of inputs to the final good, and entry of firms is governed by monopolistic competition and zero expected profits, as in Melitz (2003).

\subsection{Utility and demand}

Aggregate utility for a representative consumer is given by

$$
U=q_{0}+\sum_{j=1}^{J} \frac{Q_{j}^{\xi}}{\xi}, \quad \text { with } \quad Q_{j}=\left[\int_{i \in \omega_{j}} \phi_{j} q_{i j}^{\beta} \mathrm{d} i\right]^{1 / \beta}
$$

where $Q_{j}$ indicates an index of aggregate consumption of varieties and $\omega_{j}$ indicates the measure of the set of available varieties in sector $j$. Income of the representative consumer is assumed sufficiently high so that consumption of the standardized good, $q_{0}$, is always positive. The parameter $\beta, 0<\beta<1$, captures the consumer's willingness to substitute one variety for another, with an elasticity $1 /(1-\beta)$. For simplicity, we assume this elasticity to be uniform across sectors and that $\beta>\xi$, which implies that the substitutability among goods is larger within each sector than between sectors. This yields the following demand function for variety $i$ of the manufacturing sector $j$ :

$$
q_{i j}=Q_{j}^{-\frac{\beta-\xi}{1-\beta}} p_{i j}^{-\frac{1}{1-\beta}} \phi_{j}^{\frac{1}{1-\beta}}
$$

In equations (1) and (2), the parameter $\phi_{j}$ indicates the strength of preferences for varieties of sector $j$. We assume this to be a stochastic variable, taking on a low value of $\phi_{b}$ in a bad state of demand and a high values of $\phi_{g}=k \phi_{b}, k>1$, in a good state of demand. These values are the same for all sectors, and for all sectors the probability of each state is equal to $1 / 2 .{ }^{9}$ Outcomes are assumed to be uncorrelated across sectors. Invoking the law of large numbers, i.e., assuming a sufficiently large number of sectors, at each point in time half of the sectors are in a good state of demand and half are in

\footnotetext{
${ }^{9}$ This departs from Bagliano \& Bertola (2004) who assume that a change in the state of demand occurs with probability $1 / 2$.
} 
the bad state. ${ }^{10}$ The expected value of $\phi_{j}$ is given by $\bar{\phi}:=\phi_{b}(1+k) / 2$ and the variance is given by $\sigma^{2}:=\phi_{b}^{2}\left(k^{2} / 4-k / 2+1 / 4\right)>0$. Without loss of generality, we normalize the expected value $\bar{\phi}=1$, so that

$$
\phi_{b}=2 /(1+k) \quad \text { and } \quad \phi_{g}=2 k /(1+k) .
$$

In this specification, $k$ is a measure for the level of uncertainty in industry-specific demand. However, different degrees of uncertainty, i.e. different values of $k$, are characterized by identical levels of expected demand. The stochastic nature of demand is known to all firms prior to entry into the manufacturing sector.

\subsection{Production}

Production of the standardized good 0 takes place under constant returns to scale and perfect competition. The good is freely traded between North and South, and we assume labor endowments of the two countries to be such that both countries produce this good in positive amounts. We assume a unitary labor productivity for good 0 in North and take this good as our numéraire, so that the wage rate in North is equal to unity: $w^{N}=1$. We assume South to have an absolute disadvantage in this good, whence its wage rate is lower than in the North: $w^{S}<1$. Remember that labor is assumed to be mobile across all types of employment, hence there is a single equilibrium wage rate within each country.

Production in the manufacturing sector requires headquarter services and manufacturing components. Each of these inputs is produced with a unitary labor productivity. Quantities of these inputs are denoted by $h$ and $m$, respectively. Each firm is uniquely characterized by a productivity-level $\theta$, drawn upon entry from a distribution function $G(\theta)$, and each firm produces its own distinct variety. This allows us to replace the variety index $i$ by $\theta$, with associated input levels $h(\theta)$ an $m(\theta)$. Final output of a variety of sector

\footnotetext{
${ }^{10}$ Assuming identical probabilities for the two states of nature has the advantage that there are no fluctuations in aggregate variables, such as aggregate output or the price index.
} 
$j$ produced by a firm with productivity $\theta$ is given by

$$
q_{j}(\theta)=\theta\left[\frac{h_{j}(\theta)}{\eta_{j}}\right]^{\eta_{j}}\left[\frac{m_{j}(\theta)}{1-\eta_{j}}\right]^{1-\eta_{j}}
$$

In the following, we assume a common elasticity $\eta_{j}=\eta$ for all $j$, with $0<\eta<1$, and we use $s=g, b$ to index the state of demand. Given inverse demand (2), revenue of a firm with productivity $\theta$ depends on the state of demand $\phi_{s}$ :

$$
R\left[\theta, \phi_{s}, h(\theta), m(\theta)\right]=\phi_{s} Q^{\xi-\beta} \theta^{\beta}\left[\frac{h(\theta)}{\eta}\right]^{\beta \eta}\left[\frac{m(\theta)}{1-\eta}\right]^{\beta(1-\eta)} .
$$

whereby $\phi_{s}$ is governed by (3). Note that $\partial R[\cdot] / \partial h(\theta)=\beta \eta R[\cdot] / h(\theta)$, and similarly for input $m$. Clearly, since $0<\eta \beta<1$, marginal revenue with respect to either type of input is falling.

In contrast to Antràs \& Helpman (2004), we assume an environment of enforceable contracts. Specifically, the firm writes perfect labor contracts when hiring labor to produce the two types of inputs. In addition to these variable inputs, however, production requires that a firm incurs a fixed cost, which depends on where the manufacturing input is produced. It can either be produced in North or in South. The corresponding fixed costs are equal to $f^{N}$ and $f^{S}$, expressed in terms of the standardized good. Importantly, we assume South to be at a disadvantage regarding this fixed cost: $f^{N}<f^{S}$.

Profit maximizing firms will want to adjust employment to changes in the state of demand, but such adjustments are costly. Without going into details, we follow Bagliano \& Bertola (2004) in assuming that there is both, a hiring and a firing cost. For simplicity, we assume that the two types of cost are equal and that the cost is linear in the adjustment of employment levels. Using $\Delta m$ and $\Delta h$, respectively, to denote the change in the level of employment for the two types of inputs from the previous period, the adjustment cost is equal to $\gamma^{N}(|\Delta h|+|\Delta m|)$ if both inputs are produced in North, and equal to $\gamma^{N}|\Delta h|+\gamma^{S}|\Delta m|$ if input $m$ is produced in South. We assume South to be the more flexible of the two economies regarding employment, whence $\gamma^{S}<\gamma^{N}$. Moreover, we 
assume that $w^{N}>\gamma^{N}$ as well as $w^{S}>\gamma^{S}$, and that firms expect time-invariant wages and adjustment costs.

\subsection{Timing and decision making}

Firms are risk neutral, making their decisions based on expected profits. At the beginning of period 0 firms decide upon entry, based on the discounted present value of expected maximum future profits, using a discount rate $r$. In turn, maximum expected profits depend on the distribution function $G(\theta)$ as well as on the two states of demand, $\phi_{g}$ and $\phi_{b}$ which arise with a fifty-fifty chance, independently for each period. We assume an infinite supply of potential entrants for all sectors, such that entry occurs until expected maximum profits are equal to a fixed entry cost $f_{e}$, which is assumed equal for all sectors. Subsequent to entry, a firm learns about its idiosyncratic productivity $\theta$ and then decides about whether to stay in the market, as in Melitz (2003). Subsequent to this decision, firms decide about where to source the manufacturing input $m$. And finally, demand uncertainty is resolved successively for all periods, and firms adjust their stocks of employment in a manner that maximizes the present value of expected profits. Notice that changes in the state of demand are independent on where the firm decides to source input $m$, hence the firm will never face an incentive to reconsider its sourcing decision.

The stochastic nature of demand, coupled with the cost of adjustment for employment, introduces an inter-temporal dimension into firms' employment decisions. If the present state of demand is high, then marginal revenue is large and the firm is tempted to hire in order to produce more of both types of input in the current period. However, not only does this cause hiring cost, it will also make adjustment to a low future state of demand more costly. And according to our assumption such a change in the state of demand will take place with a positive probability.

In the following, we use $l=N, S$ to indicate the location of production for input $m$. Using $E_{t}$ to denote the expectations operator, given information as of the beginning of period $t$, and time-indexing all state-contingent variables, the discounted present 
value of expected operating profits (i.e., net of fixed costs of production) for a firm with productivity $\theta$ that sources its input $m$ in country $l$ may be written as

$$
\begin{aligned}
V_{t}^{l}= & E_{t} \sum_{i=0}^{\infty}(1+r)^{-i}\left[R\left[\theta, \phi_{t+i}, h_{t+i}(\theta), m_{t+i}(\theta)\right]-w^{N} h_{t+i}(\theta)-w^{l} m_{t+i}(\theta)\right. \\
& \left.-\gamma^{N}\left|\Delta h_{t+i}(\theta)\right|-\gamma^{l}\left|\Delta m_{t+i}(\theta)\right|\right] .
\end{aligned}
$$

This holds true for all $t=0, \ldots \infty$. The term $R\left(\theta, \phi_{t+i}\right)$ indicates revenue of a firm with productivity $\theta$, using input levels $h_{t+i}(\theta)$ and $m_{t+i}(\theta)$, facing a state of demand equal to $\phi_{t+i}$. Note that at this stage revenue is independent on the sourcing location for input $m$. Of course, equilibrium revenue will depend on whether $m$ is produced in North, or offshore in South. Hiring and firing, $\Delta h_{t+i}(\theta)$ and $\Delta m_{t+i}(\theta)$, respectively, are with respect to employment levels of the previous period $t+i-1$. Writing $\lambda_{h, t}$ for the shadow value of labor presently employed to produce input $h$, we have

$$
\lambda_{h, t}:=E_{t} \sum_{i=0}^{\infty}(1+r)^{-i}\left(\frac{\partial R\left[\theta, \phi_{t+i}, h_{t+i}(\theta), m_{t+i}(\theta)\right]}{\partial h_{t+i}(\theta)}-w^{N}\right)
$$

Thus, $\lambda_{h, t}$ is defined as the marginal effect of an additional unit of employment, keeping all hiring and firing decisions unchanged, which implies that this additional unit is retained forever; see Bagliano \& Bertola (2004), pp. 103ff. As with revenue $R$, this shadow value does not depend on where input $m$ is produced, although the equilibrium value of $\lambda_{h, t}$ will depend on the location of sourcing. A corresponding equation holds for the shadow value of labor employed in production of input $m$. Repeating this for $t+1$ and applying the law of iterative expectations, we obtain the following difference equations for the shadow values of the two inputs:

$$
\begin{aligned}
\lambda_{h, t} & =\frac{\partial R\left[\theta, \phi_{t}, h_{t}(\theta), m_{t}(\theta)\right]}{\partial h_{t}(\theta)}-w^{N}+(1+r)^{-1} E_{t}\left(\lambda_{h, t+1}\right) \\
\lambda_{m, t}^{l} & =\frac{\partial R\left[\theta, \phi_{t}, h_{t}(\theta), m_{t}(\theta)\right]}{\partial m_{t}(\theta)}-w^{l}+(1+r)^{-1} E_{t}\left(\lambda_{m, t+1}^{l}\right) .
\end{aligned}
$$

Unlike $\lambda_{h, t}$, the shadow value of labor employed for input $m$ does depend on the location 
of sourcing through $w^{l}, l=N, S$.

Remember that corresponding to the two states of demand, $\phi_{g}$ and $\phi_{b}$, there are two shadow values of labor producing $h$, which we denote by $\lambda_{h, g}$ and $\lambda_{h, b}$, respectively. Since for any period each state of demand arises with probability $1 / 2$, we have $E_{t}\left(\lambda_{h, t+1}\right)=$ $\left(\lambda_{h, g}+\lambda_{h, b}\right) / 2$. This implies that we may rewrite (8) as

$$
\lambda_{h, s}=\frac{\partial R\left[\theta, \phi_{s}, h_{s}(\theta), m_{s}(\theta)\right]}{\partial h_{t}(\theta)}-w^{N}+\frac{1}{1+r}\left(\lambda_{h, g}+\lambda_{h, b}\right) / 2, \quad s=g, b .
$$

A similar equation follows from (9). In the following, we write $\lambda_{h, s}=\lambda_{h, s}\left[\theta, \phi_{s}, h_{s}(\theta), m_{s}(\theta)\right]$ and analogously for $\lambda_{m, s}^{l}$, in order to indicate that for each state of demand the shadow values of labor for the two types of inputs depend on the productivity level of the firm and on the corresponding employment levels chosen by the firm. Remember that the superscript index $l$ indicates the location of sourcing for $m$, thus determining whether the input $m_{s}(\theta)$ is obtained at price $w^{N}$ or $w^{S}$. Denoting optimal employment levels for input $h$ in state $s$ with input $m$ sourced in $l$ by $h_{s}^{l}(\theta)$, and analogously for input $m$, an optimal employment path requires that the following inequalities must hold:

$$
\begin{array}{lll}
\lambda_{h, g}\left[\theta, \phi_{g}, h_{g}^{l}(\theta), m_{g}^{l}(\theta)\right] \leq \gamma^{N} & \text { and } & -\lambda_{h, b}\left[\theta, \phi_{b}, h_{b}^{l}(\theta), m_{b}^{l}(\theta)\right] \leq \gamma^{N} \\
\lambda_{m, g}^{l}\left[\theta, \phi_{g}, h_{g}^{l}(\theta), m_{g}^{l}(\theta)\right] \leq \gamma^{N} & \text { and } & -\lambda_{m, b}^{l}\left[\theta, \phi_{b}, h_{b}^{l}(\theta), m_{b}^{l}(\theta)\right] \leq \gamma^{l}
\end{array}
$$

The first inequalities in both lines state that in a good state of demand the employment level for the respective input ( $h$ or $m$ ) must be such that the shadow value of labor in this type of employment, i.e., the excess of marginal revenue (in expected present value terms) over the wage rate, is less than, or equal to, the hiring cost incurred in North per unit of labor hired. If it were higher, the firm would clearly want to hire more workers. The second inequalities in both lines equivalently state that in the bad state the excess of the wage rate over respective marginal revenue must, in expected present value terms, be less than, or equal to, the firing cost in country $N$ (for $h$ ) and in country $l$ ) (for $m$ ). If it were larger, then the firm would obviously have an incentive to fire workers. 
If the above weak inequalities (11) and (12) both hold with equality, then hiring and firing takes place for both types of employment whenever the state of demand switches between two periods in time. We assume this to be the case. ${ }^{11}$ It implies that in (10) we have $\lambda_{h, g}+\lambda_{h, b}=\gamma^{N}-\gamma^{N}=0$ so that the second term vanishes; similarly for the shadow value of labor in production of $m$. Substituting accordingly for the shadow values in (10) as well as the corresponding equation of input $m$, and taking derivatives in (5), we obtain the following equations that implicitly determine optimal employment levels for the two states of demand when sourcing input $m$ in country $l$ :

$$
\begin{aligned}
& h_{g}^{l}(\theta)=\frac{\beta \eta R_{g}[\cdot]}{w^{N}+\gamma^{N}}, \quad h_{b}^{l}(\theta)=\frac{\beta \eta R_{b}[\cdot]}{w^{N}-\gamma^{N}} \\
& m_{g}^{l}(\theta)=\frac{\beta(1-\eta) R_{g}[\cdot]}{w^{l}+\gamma^{l}}, \quad m_{b}^{l}(\theta)=\frac{\beta(1-\eta) R_{b}[\cdot]}{w^{l}-\gamma^{l}} .
\end{aligned}
$$

In these equations, $R_{g}[\cdot]:=R\left[\theta, \phi_{g}, h_{g}^{l}(\theta), m_{g}^{l}(\theta)\right]$ and $R_{b}[\cdot]:=R\left[\theta, \phi_{b}, h_{b}^{l}(\theta), m_{b}^{l}(\theta)\right]$. These conditions state that in the good state marginal revenue with respect to either type of input is equal to the corresponding wage rate plus the hiring cost, and in the bad state it is equal to the wage rate minus the firing cost. Since revenue is concave in input levels and increasing in $\theta$, there are unique, state-dependent optimal levels for each type of input, and a more productive firm will employ higher levels of employment for both types of input.

We can plug these optimal employment levels into the revenue function in equation (5) in order to obtain firm revenue given optimal employment levels. In the following, we denote this optimal firm revenue in state $s$ by $\tilde{R}_{s}^{l}(\theta, Q)$. Given optimal choice of employment, revenue in either of the two states of demand only depends on the firm's productivity draw and on the aggregate consumption index of the differentiated good $Q$.

$$
\begin{aligned}
& \tilde{R}_{g}^{l}(\theta, Q)=Q^{\frac{\xi-\beta}{1-\beta}}(\theta \beta)^{\frac{\beta}{1-\beta}} \phi_{g}^{\frac{1}{1-\beta}}\left[\left(w^{N}+\gamma^{N}\right)^{\eta}\left(w^{l}+\gamma^{l}\right)^{1-\eta}\right]^{\frac{-\beta}{1-\beta}} \\
& \tilde{R}_{b}^{l}(\theta, Q)=Q^{\frac{\xi-\beta}{1-\beta}}(\theta \beta)^{\frac{\beta}{1-\beta}} \phi_{b}^{\frac{1}{1-\beta}}\left[\left(w^{N}-\gamma^{N}\right)^{\eta}\left(w^{l}-\gamma^{l}\right)^{1-\eta}\right]^{\frac{-\beta}{1-\beta}} .
\end{aligned}
$$

\footnotetext{
${ }^{11}$ This implies a minimum level of both hiring and firing cost, relative to $k$, as will become evident in Lemma 1 below.
} 
Naturally, revenue in either state of demand is increasing in the firm's productivity $\theta$, but since by assumption $\xi<\beta$, it is falling in the the sector size measured through the aggregate consumption index $Q$.

Having determined employment levels in the good and the bad state, we can now derive the flow of hired and fired headquarter employees, depending on firm productivity and the sector-level consumption aggregate as

$$
\begin{aligned}
\Delta h^{l}(\theta, Q):=h_{g}^{l}(\theta, Q)-h_{b}^{l}(\theta, Q) & =\beta \eta\left(\frac{\tilde{R}_{g}^{l}(\theta, Q)}{w^{N}+\gamma^{N}}-\frac{\tilde{R}_{b}^{l}(\theta, Q)}{w^{N}-\gamma^{N}}\right), \\
\Delta m^{l}(\theta, Q):=m_{g}^{l}(\theta, Q)-m_{b}^{l}(\theta, Q) & =\beta(1-\eta)\left(\frac{\tilde{R}_{g}^{l}(\theta, Q)}{w^{l}+\gamma^{l}}-\frac{\tilde{R}_{b}^{l}(\theta, Q)}{w^{l}-\gamma^{l}}\right) .
\end{aligned}
$$

The probability of any period featuring a good state of demand is $1 / 2$. The probability of the previous period having been in good state is also equal to $1 / 2$, so the probability of a firm wanting to hire during any given period is equal to $1 / 4$, and the expected hiring cost for $h$-type employment is equal to $\gamma^{N} \Delta h^{l}(\theta, Q) / 4$. By complete analogy, the probability of the firm wanting to fire $h$-type workers in any period is equal to $1 / 4$. Hence, the expected hiring plus firing cost is equal to $\gamma^{N} \Delta h^{l}(\theta, Q) / 2$. By analogous reasoning, the expected hiring plus firing cost for $m$-type employment is equal to $\gamma^{l} \Delta m^{l}(\theta, Q) / 2$.

The previous equations assume strict equality in equations (11) and (12) above, which implies that firms will have an incentive to adjust employments for both types of inputs across states of demand. Intuitively the severity of adjustment costs is given by how $\gamma^{l}$ relates to $w^{l}$. Whether or not adjustments between the two states of demand worthwhile depends on the severity of the adjustment cost, relative to $k$ which measures the degree of volatility across the good and the bad state. More specifically, what matters is how $k$ relates to $\left(w^{N}+\gamma^{N}\right) /\left(w^{N}-\gamma^{N}\right)$ as well as $\left(w^{S}+\gamma^{S}\right) /\left(w^{S}-\gamma^{S}\right)$. The following Lemma states the precise conditions under which hiring and firing across states does in fact take place.

Lemma 1. Firms hire for both types of employment whenever a good state of demand in any one period follows after a bad state in the previous period, and vice versa, provided 
that the degree of uncertainty is sufficiently large, relative to the cost of hiring and firing. Hiring and firing takes place across the two states of demand, irrespective of where sourcing takes place, if $k>\max _{l=N, S}\left\{\left(w^{l}+\gamma^{l}\right) /\left(w^{l}-\gamma^{l}\right)\right\}$.

Proof. The statement in this Lemma means that $\Delta h^{l}$ in equation (17) and $\Delta m^{l}$ in equation (18) are both strictly positive. Hiring and firing flows of headquarter workers are strictly positive whenever

$$
\frac{\tilde{R}_{g}^{l}(\theta, Q)}{\tilde{R}_{b}^{l}(\theta, Q)}>\frac{w^{N}+\gamma^{N}}{w^{N}-\gamma^{N}},
$$

while hiring and firing flows for manufacturing workers are strictly positive whenever

$$
\frac{\tilde{R}_{g}^{l}(\theta, Q)}{\tilde{R}_{b}^{l}(\theta, Q)}>\frac{w^{l}+\gamma^{l}}{w^{l}-\gamma^{l}}
$$

With the definitions of $\tilde{R}_{g}^{l}(\theta, Q)$ and $\tilde{R}_{b}^{l}(\theta, Q)$ in equations (15) and (16) and the definition of $\phi_{g}$ and $\phi_{b}$ in equation (3) we can write the first condition as

$$
k>\left(\frac{w^{N}+\gamma^{N}}{w^{N}-\gamma^{N}}\right)^{1-(1-\eta) \beta}\left(\frac{w^{l}+\gamma^{l}}{w^{l}-\gamma^{l}}\right)^{(1-\eta) \beta}
$$

and the second condition as

$$
k>\left(\frac{w^{N}+\gamma^{N}}{w^{N}-\gamma^{N}}\right)^{\eta \beta}\left(\frac{w^{l}+\gamma^{l}}{w^{l}-\gamma^{l}}\right)^{1-\eta \beta} .
$$

If these conditions are simultaneously fulfilled, then strictly positive hiring and firing will take place across states of demand for either of the two types of labor. The two conditions require $k$ to be larger than the geometric mean of $\left(\frac{w^{N}+\gamma^{N}}{w^{N}-\gamma^{N}}\right)$ and $\left(\frac{w^{l}+\gamma^{l}}{w^{l}-\gamma^{l}}\right)$ with the different weights given on the right-hand side of inequalities (21) and (22) above. A sufficient condition for this to be true is that $k$ is larger than the larger of these two terms, i.e., if $k>\max _{l=N, S}\left\{\left(w^{l}+\gamma^{l}\right) /\left(w^{l}-\gamma^{l}\right)\right\}$.

Given the degree of uncertainty $k$, the magnitude of employment adjustment across states of demand depends on the sector size and on firm productivity, as stated in the 
following Lemma.

Lemma 2. Given that hiring and firing across states of demand does take place, the magnitude of adjustment for either type of employment is increasing in the firm productivity $\theta$, and decreasing in sector size $Q$.

Proof. From the above equations (15) through (18) it follows that for both types of employment the magnitude of adjustment is linear in the term $\left[Q^{\xi-\beta}(\beta \theta)^{\beta}\right]^{1 /(1-\beta)}$. The Lemma then follows from our assumptions $\xi<\beta$ and $0<\beta<1$.

\subsection{Firm profits and entry}

Expected periodic operating profits for the two states of demand are found by invoking revenues corresponding to optimal employment levels, as given in (15) and (16), respectively, and subtracting the total wage bill as well as the expected firing and hiring cost. For the good state and sourcing in location $l$, we have

$$
\begin{aligned}
\tilde{\pi}_{g}^{l}(\theta, Q) & =\tilde{R}_{g}^{l}(\theta, Q)-w^{N} h_{g}^{l}(\theta, Q)-w^{l} m_{g}^{l}(\theta, Q)-D \\
& =\tilde{R}_{g}^{l}(\theta)\left[1-\beta\left(\frac{w^{N} \eta}{w^{N}+\gamma^{N}}+\frac{w^{l}(1-\eta)}{w^{l}+\gamma^{l}}\right)\right]-D
\end{aligned}
$$

In these equations, $D:=\frac{\gamma^{N}}{2} \Delta h^{l}(\theta, Q)-\frac{\gamma^{l}}{2} \Delta m^{l}(\theta, Q)$. For the bad state of demand, we have

$$
\tilde{\pi}_{b}^{l}(\theta, Q)=\tilde{R}_{b}^{l}(\theta, Q)\left[1-\beta\left(\frac{w^{N} \eta}{w^{N}-\gamma^{N}}+\frac{w^{l}(1-\eta)}{w^{l}-\gamma^{l}}\right)\right]-D .
$$

Notice that although we explicitly distinguish between the good and the bad state, $\tilde{\pi}_{g}^{l}(\theta, Q)$ and $\tilde{\pi}_{b}^{l}(\theta, Q)$ involve expectations since the hiring and firing cost in the final terms of the above equations are expected cost. Inserting the amounts of hiring and firing given in equations (17) and (18) above, and collecting terms, we obtain the expected value 
of periodic profits as

$$
\begin{aligned}
E\left(\tilde{\pi}^{l}(\theta, Q)\right) & =\frac{\tilde{\pi}_{g}^{l}(\theta, Q)+\tilde{\pi}_{b}^{l}(\theta, Q)}{2} \\
& =\frac{1-\beta}{2}\left(\tilde{R}_{g}^{l}(\theta, Q)+\tilde{R}_{b}^{l}(\theta, Q)\right)
\end{aligned}
$$

Interestingly, this model with hiring and firing cost delivers a result familiar from standard monopolistic competition, viz. that maximum profits are equal to a fraction of revenue, where this fraction is equal to $1-\beta$, the inverse of the elasticity of demand. And since we are looking at expected profits over the two states of demand, each arising with probability $1 / 2$, the relevant revenue in $(25)$ is the average across the good and the bad state. Using equations (15) and (16) and the definitions of $\phi_{g}$ and $\phi_{b}$ in equation (3), we obtain

$$
\begin{aligned}
E\left(\tilde{\pi}^{l}(\theta, Q)\right) & =\Theta\left[\left(\frac{k}{1+k}\left(\Omega_{g}^{l}\right)^{-\beta}\right)^{\frac{1}{1-\beta}}+\left(\frac{1}{1+k}\left(\Omega_{b}^{l}\right)^{-\beta}\right)^{\frac{1}{1-\beta}}\right], \\
\text { where } \Omega_{g}^{l} & :=\left(w^{N}+\gamma^{N}\right)^{\eta}\left(w^{l}+\gamma^{l}\right)^{1-\eta} \\
\Omega_{b}^{l} & :=\left(w^{N}-\gamma^{N}\right)^{\eta}\left(w^{l}-\gamma^{l}\right)^{1-\eta}, \\
\text { and } \Theta & :=(1-\beta) 2^{\frac{\beta}{1-\beta}}(\theta \beta)^{\frac{\beta}{1-\beta}} Q^{\frac{\xi-\beta}{1-\beta}} .
\end{aligned}
$$

Only firms with a productivity draw $\theta$ high enough to ensure positive firm profits remain active in the market. Let us define the expected profits, net of fixed costs $f^{l}$, earned from a firm's optimal offshoring decision as

$$
E(\tilde{\pi}(\theta, Q))=\max _{l=\{N, S\}}\left\{E\left(\tilde{\pi}^{l}(\theta, Q)\right)-f^{l}\right\}
$$

This allows us to implicitly define the minimum productivity level required for positive profits $\underline{\theta}$ by the condition that no firm enters the market if expected profits from both of the two production modes are negative. The profits of the marginal firm staying in the market subsequent to entry must therefore be equal to zero

$$
E(\tilde{\pi}(\underline{\theta}, Q))=0
$$


All firms with a productivity draw $\theta<\underline{\theta}$ will exit immediately, forfeiting the fixed entry cost $f_{e}$ already paid in advance. These profits also depend on the product market characteristics summarized by the mass of available varieties $Q$. This mass of varieties is determined by the condition that the expected present value of profits from production must be sufficient to cover fixed entry costs from the mass of firms that decides to draw from the productivity lottery. Denoting the distribution from which firms can draw by $G(\theta)$, this condition may be written as

$$
\frac{1+r}{r} \int_{\underline{\theta}}^{\infty} E(\tilde{\pi}(\theta, Q)) \mathrm{d} G(\theta)=f_{e}
$$

which provides an implicit solution for $Q$ from which all other variables can be obtained: the cutoff-level for entry, $\underline{\theta}$, the cutoff-level for offshoring (see below), as well as firmspecific revenues, profits and employment for the two states of demand.

The remaining equilibrium condition relates to the labor market, but this is implied by our assumption that the labor endowment of both economies is large enough for them to be diversified, given the assumed productivity difference in the numéraire sector 0 . Hence, for the purposes of this paper we may indeed treat the wage rates $w^{S}$ and $w^{N}$ as given. Finally, we may note that the balanced trade condition will be met, provided that households observe their budget constraint and spend all of their income on present consumption. Note also that the entire household income will be labor income since all profits made by firms staying in the differentiated goods market are absorbed, through a perfect capital market, in order to finance the fixed entry cost of firms that fail to produce due to a low productivity level. This is familiar from Melitz (2003). 


\section{Optimal sourcing strategy}

In the introduction, we have emphasized that the presence of demand uncertainty, coupled with adjustment frictions in the form of a hiring and firing cost, generates an important additional concern when it comes to the location of sourcing, over and above the desire to arbitrage over factor cost differences that is at the heart of existing models of offshoring. The model developed in the preceding section allows us to address this concern. Obviously, the labor market institutions responsible for hiring and firing cost can reinforce or undermine a factor cost advantage of offshoring, or they can compensate for a factor cost disadvantage of offshoring. To fix ideas, we assume that South has a factor cost advantage that derives from a lower wage rate, $w^{N}>w^{S}$, which in turn derives from a productivity gap vis à vis North in the traded numéraire good 0. Moreover, we assume that the fixed cost of production is larger if the firm (by assumption always headquartered in North) sources the manufacturing input in South, $f^{N}<f^{S}$.

\subsection{Selection of firms into offshoring}

In order to shed light on the trade offs involved in offshoring implied by our model, we now return to the decision highlighted by (27). To identify the new adjustment cost channel in this decision, let us for the time being assume away any factor cost advantage of offshoring by setting $w^{N}=w^{S}$. Obviously, in a world without uncertainty no firm would then ever want to offshore production of the manufacturing component, given that this would generate a higher fixed cost. However, a lower hiring and firing cost, $\gamma^{S}<\gamma^{N}$, will generate an advantage of offshoring which will be high enough to overcompensate the higher fixed cost associated with offshoring, provided that the degree of uncertainty is large enough and the firm sufficiently productive. We anchor our results in a fixed wage rate as well as firing and hiring cost in North, $w^{N}$ and $\gamma^{N}$, and for future reference, we define $\Pi^{N}(\theta, Q):=E\left(\tilde{\pi}^{N}(\theta, Q)\right)+f^{S}-f^{N}$. Thus, $E\left(\tilde{\pi}^{S}(\theta, Q)\right)=\Pi^{N}(\theta, Q)$, with $E\left(\tilde{\pi}^{S}(\theta, Q)\right)$

determined as in $(26)$ for $l=S$, describes a situation where a firm with productivity 
level $\theta$ would just be indifferent between domestic and foreign sourcing. Note that, given $w^{N}$ and $\gamma^{N}, E\left(\tilde{\pi}^{S}(\theta, Q)\right)$ depends on the two aforementioned variables determining the advantage of sourcing the manufacturing component in South: $w^{S}$ and $\gamma^{S}$.

Proposition 1 (offshoring and labor market flexibility). For any wage rate and firing/hiring cost in South, $w^{S}$ and $\gamma^{S}$, a) a marginal reduction in $\gamma^{S}$ increases operating profits achieved with offshore sourcing of the manufacturing component, $E\left(\tilde{\pi}^{S}(\theta, Q)\right)$, provided that the degree of uncertainty is high enough for hiring and firing of manufacturing workers across states of demand to be worthwhile, b) a marginal reduction in $w^{S}$ unambiguously increases $E\left(\tilde{\pi}^{S}(\theta, Q)\right)$. c) The marginal effects according to both a) and b) are magnified by a firm's productivity level $\theta$. d) For $w^{S}=w^{N}$ and any $\gamma^{S}<\gamma^{N}$, there exists a finite productivity level $\theta^{*}$ such that all firms with $\theta<\theta^{*}$ will choose an offshoring mode of production, provided the condition of part b) is satisfied.

Proof. To prove parts a) and b) of the proposition, we take derivatives of $E\left(\tilde{\pi}^{S}(\theta, Q)\right)$ as given in (26), setting $w^{l}=w^{S}$ and $\gamma^{l}=\gamma^{S}$. It is relatively straightforward to show that

$$
\begin{aligned}
& \frac{\partial E\left(\tilde{\pi}^{l}(\theta, Q)\right)}{\partial \gamma^{S}}=\Theta \frac{(1-\eta) \beta}{1-\beta}\left[\left(\frac{B}{1+k}\right)^{\frac{1}{1-\beta}}-\left(\frac{k G}{1+k}\right)^{\frac{1}{1-\beta}}\right] \\
& \frac{\partial E\left(\tilde{\pi}^{l}(\theta, Q)\right)}{\partial w^{S}}=-\Theta \frac{(1-\eta) \beta}{1-\beta}\left[\left(\frac{B}{1+k}\right)^{\frac{1}{1-\beta}}+\left(\frac{k G}{1+k}\right)^{\frac{1}{1-\beta}}\right]
\end{aligned}
$$

In these equations $B:=\left(w^{N}-\gamma^{N}\right)^{-\eta \beta}\left(w^{S}-\gamma^{S}\right)^{\eta \beta-1}$ and $G:=\left(w^{N}+\gamma^{N}\right)^{-\eta \beta}\left(w^{S}+\gamma^{S}\right)^{\eta \beta-1}$. Given that $w^{l}-\gamma^{l}$ for both $l=N, S$ as assumed, the second derivative directly proves part b) of the proposition. For the derivative in the first line to be negative as stated in part a), we must have $B<k G$, which implies

$$
k>\frac{\left(w^{N}-\gamma^{N}\right)^{-\eta \beta}\left(w^{S}-\gamma^{S}\right)^{\eta \beta-1}}{\left(w^{N}+\gamma^{N}\right)^{-\eta \beta}\left(w^{S}+\gamma^{S}\right)^{\eta \beta-1}}
$$

Comparing this with (22), it is identified as the condition for positive hiring and firing of manufacturing workers across states of demand according to Lemma 1 above, which proves part b) of the proposition. Part c) is obvious from the definition of $\Theta$ as given 
in connection with (26) above. Finally, part d) of the proposition may be demonstrated by approximating $\left.E\left(\tilde{\pi}^{S}(\theta, Q)\right)\right|_{\gamma^{S}, w^{S}=w^{N}} \approx E\left(\tilde{\pi}^{N}(\theta, Q)\right)+\frac{\partial E\left(\tilde{\pi}^{l}(\theta)\right)}{\partial \gamma^{S}}\left(\gamma^{S}-\gamma^{N}\right)>0$. The inequality follows if the condition for part b) of the proposition is satisfied. Given that the second term in this approximation is monotonically increasing in $\theta$, there exists a finite value $\theta^{*}$ such that the second term is equal to $f^{S}-f^{N}$, which proves part $\mathrm{d}$ ).

Figure 1 illustrates Proposition 1 by plotting combinations $\left(\gamma^{S}, w^{S}\right)$ that deliver a constant value of $E\left(\tilde{\pi}^{S}(\theta, Q)\right)-\Pi^{N}(\theta, Q)$ for alternative levels of firm productivity $\theta$ and for given values of $\gamma^{N}$ and $w^{N}$. Note that $\gamma^{S}$ and $w^{S}$ do not enter the offshoring calculus symmetrically as the slopes of these lines are larger than 1 in absolute value. ${ }^{12}$ Note that the lines are drawn as straight lines only for simplicity. The solid line passing through point $\left(\gamma^{N}, w^{N}\right)$ separates the $\gamma^{S}-w^{S}$-space into a subspace (to the northwest) where firms abstain from offshoring, no matter what their productivity level, and a remaining subspace where firms select themselves into offshoring and wholly domestic production depending on their productivity level. If the domain of $G(\theta)$ has no finite upper bound, then a marginal downward deviation of $\gamma^{S}$ from $\gamma^{N}$ will be enough for some firms to take up offshoring, even if there is no wage advantage in South, $w^{S}=w^{N}$. This is part d) of Proposition 1, highlighted in Figure 1 by the dotted line, representing a cutoff productivity level equal to $\theta_{1}^{*}$. Any combination $\left(\gamma^{N}, w^{N}\right)$ to the southwest of this line reduces the cutoff level of $\theta$ that separates offshoring firms from the rest, as depicted by the dashed line for $\theta_{2}^{*}$. Given our assumption $f^{S}>f^{N}$ it will always be the more productive firms that engage in offshoring.

\footnotetext{
${ }^{12}$ More specifically, from the proof of Proposition 1 it is straightforward to see that the slope of these lines is equal to

$$
\mathrm{d} \gamma^{S} / \mathrm{d} w^{S}=\left[\left(\frac{B}{1+k}\right)^{\frac{1}{1-\beta}}+\left(\frac{k G}{1+k}\right)^{\frac{1}{1-\beta}}\right] /\left[\left(\frac{B}{1+k}\right)^{\frac{1}{1-\beta}}-\left(\frac{k G}{1+k}\right)^{\frac{1}{1-\beta}}\right]<-1
$$

where the inequality assumes that the condition for nonzero hiring/firing is met.
} 


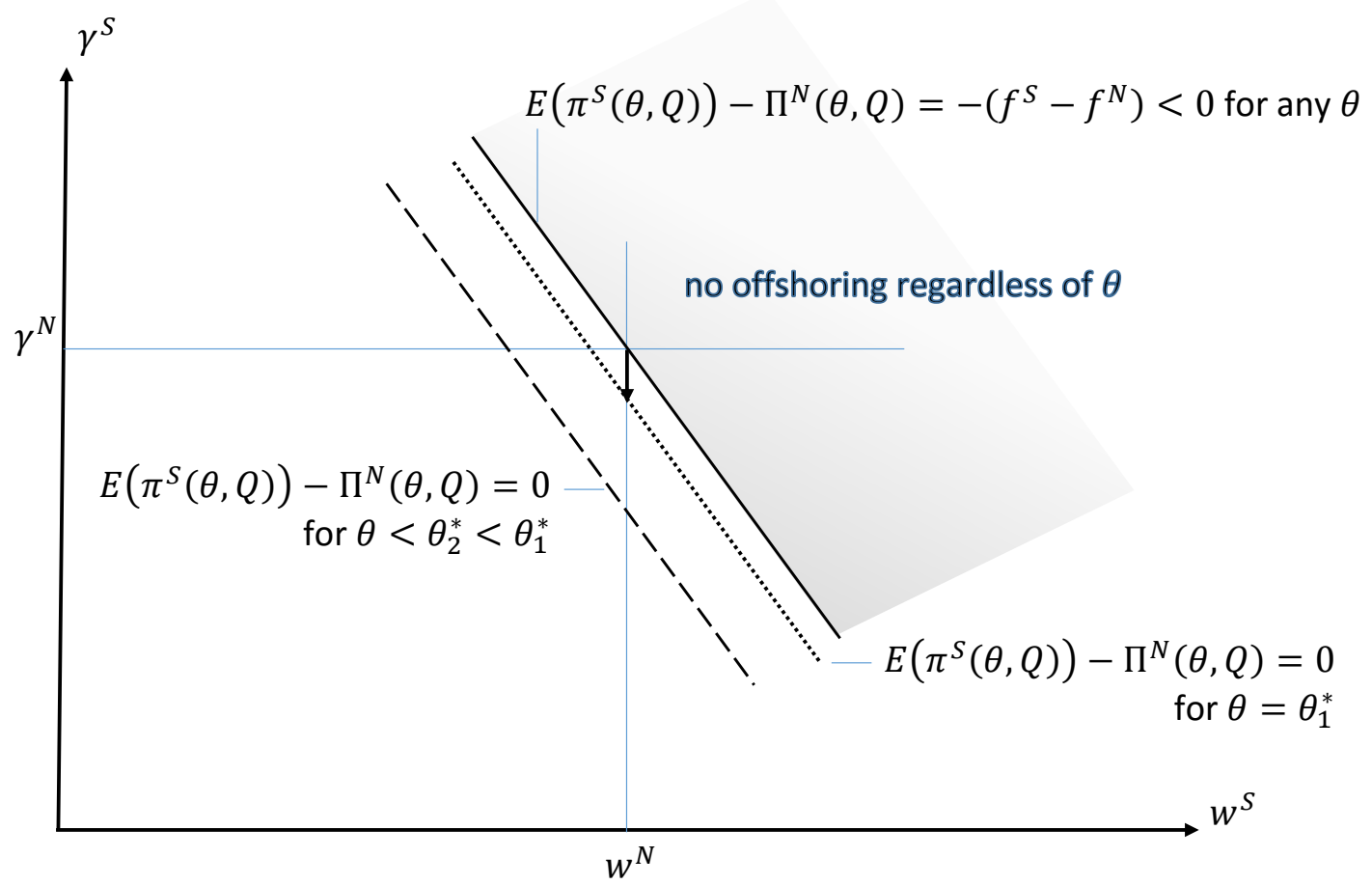

Figure 1. Offshoring, wage rates and hiring/firing cost

\subsection{Does higher uncertainty increase the incentive for offshoring?}

In our model the degree of uncertainty is represented by the parameter $k$ which measures the percentage deviation of the good from the bad state of the demand parameter $\phi_{s}$. We synonymously refer to $k$ as the degree of uncertainty of the volatility of demand. Given a certain combination $\left(\gamma^{S}, w^{S}\right)$ that has some firms in North offshoring production of the manufacturing component to South, how does the cutoff level of firm productivity change if the degree of demand uncertainty is increasing? Will there be more offshoring in a more uncertain world?

To answer this question, we first explore what an increase in the degree of uncertainty does to expected maximum profits as given in (26).

Lemma 3. An increase in the degree of uncertainty, $d k>0$, leads to an increase in expected maximum profits for either type of sourcing, $E\left(\tilde{\pi}^{l}(\theta, Q)\right)$ for $l=N, S$, provided that the initial degree of uncertainty, relative to the hiring and firing cost, is large enough for strictly positive hiring and firing to take place for either type of employment. 
Proof. It is relatively straightforward to show that

$$
\frac{\partial E\left(\tilde{\pi}^{l}(\theta, Q)\right)}{\partial k}=\frac{\Theta}{1-\beta}\left(\frac{1}{1+k}\right)^{\frac{2-\beta}{1-\beta}}\left[k^{\frac{\beta}{1-\beta}}\left(\Omega_{g}^{l}\right)^{\frac{-\beta}{1-\beta}}-\left(\Omega_{b}^{l}\right)^{\frac{-\beta}{1-\beta}}\right] .
$$

This is positive if and only if

$$
k>\left(\frac{\Omega_{b}^{l}}{\Omega_{g}^{l}}\right)^{-1}=\frac{\left(w^{N}+\gamma^{N}\right)^{\eta}\left(w^{l}+\gamma^{l}\right)^{1-\eta}}{\left(w^{N}-\gamma^{N}\right)^{\eta}\left(w^{l}-\gamma^{l}\right)^{1-\eta}} .
$$

Comparing this with the condition in Lemma 1, we recognize the aforementioned convexity property, provided that positive hiring and firing takes place across states of demand.

The intuition for this lemma 3 is easy to obtain by recognizing that $E\left(\tilde{\pi}^{l}(\theta, Q)\right)$ increasing in $k$ reflects convexity of the maximum profit function $\left.\tilde{\pi}^{l}(\theta, Q)\right)$ in $k$. In this model where firms have market power a change in the state of demand is comparable to a change in the price in a case where firms face perfect competition. And it is well known that under perfect competition, the maximum profit function is convex in prices. Even though adjusting to a change in demand is costly, provided that it pays for a firm to adjust, in expectation it will benefit more from positive demand shocks than it will be harmed by negative demand shocks. And this gain will obviously be the larger, the larger the magnitude of the shocks. To see what this implies for offshoring, we must look at the condition determining the cutoff productivity level that makes a firm indifferent between offshoring and domestic sourcing:

$$
E\left(\tilde{\pi}^{S}(\theta, Q)\right)-E\left(\tilde{\pi}^{N}(\theta, Q)\right)=f^{S}-f^{N}
$$

Convexity of the profit function in $k$ implies that both terms on the left-hand side of equation (32) increase with an increase in $k$. If they increase by equal proportions, any profit advantage from offshoring will be magnified, so that offshoring becomes more attractive, and the cutoff-level of productivity will be lowered. More generally, we may state the following Proposition: 
Proposition 2 (offshoring and the degree of uncertainty). Assuming that some firms engage in offshoring to start with, an increase in the degree of uncertainty (volatility of demand), $\mathrm{d} k>0$, leads to a reduction in the cutoff-level of productivity that separates offshoring from purely domestic firms, $\mathrm{d} \theta^{*}<0$, provided (i) that the degree of uncertainty is large enough to generate positive amounts of hiring and firing in response to demand shocks, and provided (ii) that North features a low relative labor market flexibility such that $\gamma^{N} / \gamma^{S} \geq w^{N} / w^{S}$.

Proof. See the Appendix.

Intuitively, for a rise in demand volatility to benefit offshoring firms more than domestic firms, South must offer a minimum degree of labor market flexibility, relative to North. What matters, however, is not the absolute amount of hiring and firing cost in the two countries, but the ratio of $\gamma^{l} / w^{l}$. Only if $\gamma^{S} / w^{S}<\gamma^{N} / w^{N}$, which condition (iii) of Proposition 2 calls a low relative labor market flexibility of North, will firms with a productivity level just below the existing cutoff level $\theta^{*}$ discover, upon an increase in the degree of uncertainty, that a switch to an offshoring production mode is worth the extra fixed cost according to condition (32).

Corollary 1. Starting out from a situation where offshoring takes place with North and South featuring the same labor market flexibility, $\gamma^{S}=\gamma^{N}$, any increase in demand volatility will increase offshoring at the extensive margin. If the same initial margin of offshoring is reached with North and South featuring the same wage rate, $w^{S}=w^{N}$, any increase in demand volatility will reduce offshoring at the extensive margin.

The situation is illustrated in Figure 2. Points A and B both deliver indifference between offshoring and wholly domestic production, respectively, for a firm with a productivity level equal to $\theta_{2}^{*} .{ }^{13}$ If $k$ increases, the indifference locus for this firm shifts to the right if South is at point A, whereas it shifts to the left if South is at point B. As a result of a higher $k$, at $\mathrm{A}$ the cutoff-level will shift to some value below $\theta_{2}^{*}$, whereas at

\footnotetext{
${ }^{13}$ Remember, however, that such iso-profit lines are no straight lines.
} 


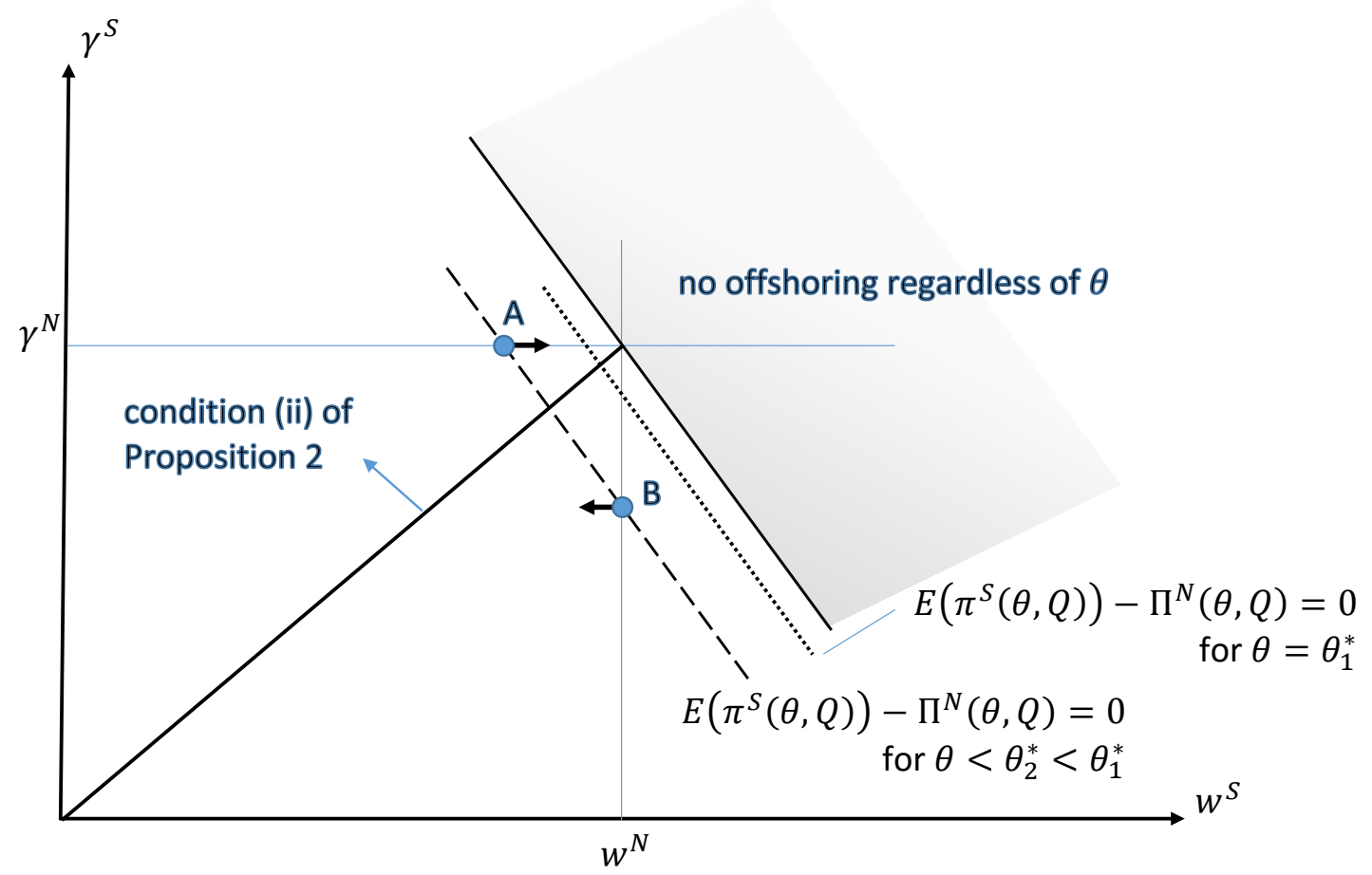

Figure 2. Pro-offshoring increase in volatility

$\mathrm{B}$ it will rise to a value above $\theta_{2}^{*}$. More generally, the conclusion at this stage is that if offshoring is primarily driven by differential labor market flexibility, then an increase in the volatility of demand will have a pro-offshoring effect, and vice versa if offshoring is primarily driven by a direct wage cost advantage.

The model is suggestive of an empirical prediction that can be brought to the data. Generalizing the setup to multiple source countries for offshoring and/or to several industries, we would expect to see a positive correlation between the industry-specific degree of volatility and the labor market flexibility of the source country interacted with that country's labor market flexibility relative to its wage rate, reasonably proxied by its GNP per hour worked. 


\section{Offshoring and employment volatility}

We have developed this model, in order to shed light on the relationship between offshoring and employment volatility. This question has been addressed by Bergin et al. (2011) who develop a model that is able to explain the high volatility of employment in Mexico's maquiladoras, relative to the volatility of employment in US industries who offshore to these maquiladoras. Their model features demand shocks similar to the ones considered here, but it abstracts from costs of hiring and firing that are associated with adjustment to these shocks. We now address the issue of employment volatility in our model where differential labor market flexibility is a key driver of offshoring. More specifically, we shall answer the following questions: Given a certain degree of demand volatility, do offshoring firms exhibit a higher volatility of headquarter employment than non-offshoring firms? Do offshoring firms exhibit a higher degree of volatility in their offshore manufacturing employment than in their domestic headquarter employment? How does change in the wage or the firing cost in North affect the volatility of employment in offshoring and non-offshoring firms?

These questions are of obvious importance, given policy makers' concern about stability of employment relationships. But we should like to express a caveat at the outset. Stabilizing employment in the presence of demand uncertainty through imposing a hiring/firing tax equal to $\gamma^{N}$ imposes a welfare loss to start with. ${ }^{14}$ Policy makers face a trade-off between the benefit of more stable employment relationships and the welfare cost of a discrepancy between the marginal value product of labor for either type of use and its true opportunity cost. Modeling this trade-off would require risk aversion in household preferences, which is not the case with (1). Analyzing a policy of optimal employment stabilization in an environment with risk averse households is beyond the scope of this paper. However, based on the present analysis as far as it goes, it should be clear that an increase in employment volatility in North, generated by whatever exogenous shock, will be devoid of any first order welfare effect if the hiring/firing policy is designed as

\footnotetext{
${ }^{14}$ For details, see Bagliano \& Bertola (2004).
} 
an optimal policy along the aforementioned trade-off. Moreover, given policy makers' ability to run such a policy, we would expect them to readjust this policy after the shock. An alternative interpretation of our model would view $\gamma^{N}$ and $\gamma^{S}$ as representing real cost incurred, in which case the hiring/firing decisions are undistorted and a change in volatility is similarly devoid of a first order welfare effect.

These reservations notwithstanding, it still seems worthwhile to explore whether offshoring driven by arbitraging over differential labor market flexibility and different wage cost, as modeled in this paper, will have a stabilizing effect on domestic employment, or whether it it magnifies the degree of domestic employment volatility, given the underlying degree of uncertainty in demand. Employment adjustments between the good and bad states of demand, respectively, for the two types of employment, headquarter employment $h$ and manufacturing employment $m$, are given in equations (17) and (18). Obviously, the magnitude of these adjustments is larger for a larger aggregate market size $Q$ and for a higher firm-level employment and, thus, for a higher firm productivity $\theta$. For the present purpose, it seems desirable do use a measure of employment volatility that is independent of both aggregate market size and firm productivity. We therefore measure volatility through the flows connecting the good and the bad states of demand as given in (17) and (18), relative to the mean of the stocks of employment in the two states. From (13), mean employment over both states of demand is written as

$$
\bar{h}^{l}(\theta):=\frac{1}{2}\left(h_{g}^{l}(\theta)-h_{b}^{l}(\theta)\right)=\frac{\beta \eta}{2}\left(\frac{\tilde{R}_{g}^{l}(\theta)}{w^{N}+\gamma^{N}}+\frac{\tilde{R}_{b}^{l}(\theta)}{w^{N}-\gamma^{N}}\right),
$$

and analogously for $\bar{m}^{l}(\theta)$. In this equation and all others following below, we oppress the sector size $Q$. Combining this with (17), our measure of employment volatility for the two types of employment emerge as

$$
\begin{aligned}
\hat{h}^{l} & :=\frac{\Delta h^{l}(\theta)}{\bar{h}^{l}(\theta)}=2\left(\frac{\left(w^{N}-\gamma^{N}\right) \tilde{R}_{g}^{l}(\theta)-\left(w^{N}+\gamma^{N}\right) \tilde{R}_{b}^{l}(\theta)}{\left(w^{N}-\gamma^{N}\right) \tilde{R}_{g}^{l}(\theta)+\left(w^{N}+\gamma^{N}\right) \tilde{R}_{b}^{l}(\theta)}\right), \\
\hat{m}^{l} & :=\frac{\Delta m^{l}(\theta)}{\bar{m}^{l}(\theta)}=2\left(\frac{\left(w^{l}-\gamma^{l}\right) \tilde{R}_{g}^{l}(\theta)-\left(w^{l}+\gamma^{l}\right) \tilde{R}_{b}^{l}(\theta)}{\left(w^{l}-\gamma^{l}\right) \tilde{R}_{g}^{l}(\theta)+\left(w^{l}+\gamma^{l}\right) \tilde{R}_{b}^{l}(\theta)}\right) .
\end{aligned}
$$


Reading the state-contingent revenues appearing in (34) from equations (15) and (16), we recognize that these measures of employment volatility are independent on $Q$ and $\theta$, but are importantly driven by $k$ the degree of uncertainty in firm specific demand shocks, as expected. To see this, observe the role of $\phi_{g}$ and $\phi_{b}$ in equations (15) and (16) as well as equation (3). Finally, notice that with the normalization underlying $\hat{h}^{l}$ and $\hat{m}^{l}$, these measures as well as the separation between offshoring and non-offshoring firms, fully describe aggregate employment volatility.

In the introduction we have raised the question of what an increase in openness to offshoring does to an economy's employment volatility, given that differential labor market flexibility is an important driver of offshoring, in addition to the more conventional idea of arbitraging on wage cost differences. Armed with the above measures of employment volatility, $\hat{h}^{l}$ and $\hat{m}^{l}$, we are now able to answer this question. Suppose, then, that lower barriers to offshoring lead to a reduction in $f^{S}$. This makes entry more attractive, driving up the cutoff level for surviving firms, $\bar{\theta}$. It will also drive up the cutoff level $\theta^{*}$ that separates offshoring from non-offshoring firms. However, given that the average productivity of offshoring and non-offshoring firms does not play any role for employment volatility as defined here, the effect of this pro-offshoring scenario on employment volatility in North only depends on whether or not $\hat{h}^{S}>\hat{h}^{N}$. If this inequality holds, than the volatility of headquarter employment is larger for firms that are engaged in offshoring than for firms producing the manufacturing component domestically in North. In this case, if the extensive firm margin of offshoring is shifting as described above, making some firms switch from domestic to offshore provision of $m$, then aggregate volatility of headquarter employment is increasing.

What if at the same time we have $\hat{m}^{S}>\hat{m}^{N}$ ? While this does imply that manufacturing employment in offshoring firms is more volatile than in non-offshoring firms, it does not mean that the shift in the extensive margin of offshoring contributes to volatility in North. The reason simply is that $\hat{m}^{S}$ contributes to volatility in South, not in North. What matters for overall employment volatility in North, in addition to whether or not 
$\hat{h}^{S}>\hat{h}^{N}$, is whether $\hat{h}^{N}$ is larger or smaller than $\hat{m}^{N}$. If $\hat{h}^{N}$ were larger than $\hat{m}^{N}$ to start with, then some firms shifting from $l=N$ to $l=S$ would mean that the overall share of northern workers who are employed in manufacturing (featured by low volatility) is reduced, and the share of workers employed in headquarters (featured by high volatility) is increasing. However, inspection of (34) and (35) tells us that we actually have $\hat{h}^{N}=\hat{m}^{N}$. This means that $\hat{h}^{S}>\hat{h}^{N}$ does in fact imply a higher aggregate volatility of employment in a scenario of more firms engaging in offshoring as a result of lower fixed cost $f^{S}$. We may summarize the relationship between offshoring and volatility by the following proposition.

Proposition 3 (offshoring and employment volatility). a) The volatility of headquarter employment in offshoring firms is larger than in non-offshoring firms, if North features a relatively inflexible labor market, i.e., if $\gamma^{N} / \gamma^{S}>w^{N} / w^{S}$. b) Under the exact same condition, volatility of manufacturing employment in South is larger than manufacturing employment in North. c) Under the exact same condition, a reduction in the fixed cost of offshoring, $\mathrm{d} f^{S}<0$, aggravates employment volatility in North.

Proof. For part a) we must show $\hat{h}^{S}>\hat{h}^{N}$. From (34) it is straightforward that this implies

$$
\frac{\tilde{R}_{g}^{S}(\theta)}{\tilde{R}_{b}^{S}(\theta)}>\frac{\tilde{R}_{g}^{N}(\theta)}{\tilde{R}_{b}^{N}(\theta)}
$$

Inserting from (15) and (16), suitably setting $l=S$ and $l=N$, we may write

$$
\frac{\tilde{R}_{g}^{S}(\theta) / \tilde{R}_{b}^{S}(\theta)}{\tilde{R}_{g}^{N}(\theta) / \tilde{R}_{b}^{N}(\theta)}=\left(\frac{\left(w^{N}+\gamma^{N}\right) /\left(w^{N}-\gamma^{N}\right)}{\left(w^{S}+\gamma^{S}\right) /\left(w^{S}-\gamma^{S}\right)}\right)^{\frac{\beta(1-\eta)}{1-\beta}}>1
$$

Since $\frac{\beta(1-\eta)}{1-\beta}>0$, this implies $\left(w^{N}+\gamma^{N}\right) /\left(w^{N}-\gamma^{N}\right)>\left(w^{S}+\gamma^{S}\right) /\left(w^{S}-\gamma^{S}\right)$. Multiplying out, we obtain $\gamma^{N} / \gamma^{S}>w^{N} / w^{S}$ as stated in the proposition. The proof of part b) requires that we show $\hat{m}^{S}>\hat{m}^{N}$, based on (35). It is obvious that the logic of a) also applies to this part of the proposition. Part c) follows from the $\hat{h}^{N}=\hat{m}^{N}$ and $\hat{h}^{S}>\hat{h}^{N}$, coupled with the above mentioned changes in the cutoff levels: the cutoff level for firm survival increases while the offshoring cutoff falls, whence the share of firms 
with an offshore production mode unambiguously increasing. $\hat{h}^{N}=\hat{m}^{N}$ means that the ensuing inframarginal reallocation from manufacturing to headquarter employment leaves employment volatility unaffected, while $\hat{h}^{S}>\hat{h}^{N}$ means that at the margin firms that newly take up offshoring will exhibit a higher volatility of domestic headquarter employment.

This proposition may seem counterintuitive at first sight. Firms' adjustment to demand shocks is partly absorbed by the foreign labor market, yet the outcome is a more volatile domestic employment. However, the intuition is relatively straightforward once it is recognized that under the conditions of Proposition 3 offshoring is driven by South featuring a relatively flexible labor market. The point is that for this reason the adjustment of manufacturing employment to demand shocks will be larger for firms that are engaged in offshoring than for domestic firms subject to the more rigid labor market in North. While this does not per se contribute to employment volatility in North, it does mean that the marginal productivity of headquarter employment in North will be subject to larger shocks, even for an unchanged magnitude of the demand shocks, simply because the two inputs (manufacturing component and headquarter service) are complements in production. In this sense, offshoring may be viewed a leverage that makes the more flexible labor market in South being felt in terms of higher volatility also in North, even for a given labor market rigidity in North and for a given degree of volatility in the underlying demand shocks.

Corollary 2. Starting out from a situation where offshoring takes place with North and South featuring the same labor market flexibility, $\gamma^{S}=\gamma^{N}$, a fall in the fixed cost of offshoring will lead to a higher employment volatility in North. If the same initial margin of offshoring is reached with North and South featuring the same wage rate, $w^{S}=w^{N}$, then a reduction in the fixed cost of offshoring will reduce employment volatility in North.

It would seem that Proposition 3 holds a message that is relevant beyond the narrow confines of the present model. Moreover, it should be relatively straightforward to bring the essence of this proposition to the data. Suppose, for instance, that we have a firm- 
level data set that allows us to trace employment volatility as measured in the proposition. Suppose, moreover, that we observe firms engaged in offshoring as well as non-offshoring firms and for offshoring firms we are able to identify the source country. Finally, let us assume that we can separate the source countries into two subsets, one where the relative flexibility of the labor market is higher than in the home country, and the complementary set where it is lower. Then, for the first subset our model would predict that we find (i) the degree of employment volatility to be larger for offshoring firms than for non-offshoring firms belonging to the same industry and (ii) the volatility of offshoring firms to be the larger, the more volatile the industry that they belong to. For the second subset, the model would deliver corresponding predictions the run in the opposite directions.

\section{Conclusion}

In this paper, we address offshoring in an environment characterized by uncertainty coupled with labor market rigidities that generate adjustment costs for employment. Borrowing from Bagliano \& Bertola (2004), we develop a model where employment levels for two different parts of the value added process are jointly determined through intertemporal optimization, based on an underlying degree of uncertainty regarding the state of demand and on certain hiring and firing costs generated by labor market rigidity. The offshoring decision then responds to differential degrees of labor market rigidities, in addition to differences in wage rates. More specifically, if the foreign labor market features less costly adjustments to changes in the state of demand, this generates an advantage of offshoring that may reinforce the wage advantage, or compensate for a wage disadvantage. Our model features firm heterogeneity as in Melitz (2003), and we show that for a given degree of uncertainty and flexibility of the labor market the magnitude of a firm's employment adjustment across states of demand is increasing in its productivity level. Moreover, the advantages deriving from a higher degree of flexibility or from a lower wage rate are both increasing in firm productivity. Jointly, these advantages generate a unique cutoff level of productivity that separates firms that engage in offshoring from firms producing 
both parts of value added domestically.

In such an environment, an interesting question to ask is whether an increase in the degree of uncertainty will be pro-offshoring, or will instead attenuate firms' incentives to pursue offshoring. We show that what matters here is whether or not offshoring is mainly driven by a low relative labor market rigidity in the foreign economy, whereby relative labor market rigidity is measured by the ratio of a country's firing (or hiring) cost to that country's wage rate. Specifically, if the foreign economy is featured by a low degree of relative labor market rigidity compared to the domestic economy, then an increase in the degree of uncertainty, measured through the magnitude of demand shocks, will cause more firms to take up offshoring.

A further issue arising in such an environment is what offshoring does to the volatility of domestic employment. One might be tempted to think that offshoring should reduce volatility since it partly shifts the burden of adjustment to the foreign economy. However, this intuition does not necessarily survive in general equilibrium reasoning, for two reasons. First, offshoring implies reallocation from one part of the value added process (moving offshore) to the remaining part which remains in the domestic economy, and is not clear a priori which of the two parts features a higher degree of volatility, given the underlying demand uncertainty. And secondly, if offshoring is indeed taking place in an environment where the foreign economy has a more flexible economy, then offshoring firms will react more strongly to demand shocks than purely domestic firms, since they face lower adjustment cost. Plausibly, their enhanced flexibility in the foreign part of their value added process might also lead them to be more flexible in their remaining domestic part. We demonstrate that this is indeed the case, if we measure volatility by the magnitude of employment adjustment, relative the average employment levels across states of demand. 


\section{References}

Anderson, James E. 2011. The specific factors continuum model, with implications for globalization and income risk. Journal of International Economics, 85(2), 174 - 185.

Antràs, Pol. 2015. Global Production: Firms, Contracts, and Trade Structure. Princeton University Press.

Antràs, Pol, \& Helpman, Elhanan. 2004. Global Sourcing. Journal of Political Economy, 112(3), 552-580.

Antràs, Pol, \& Yeaple, Stephen R. 2014. Chapter 2 - Multinational Firms and the Structure of International Trade. Pages 55 - 130 of: Elhanan Helpman, KenNeth Rogoff, \& Gopinath, Gita (eds), Handbook of International Economics. Handbook of International Economics, vol. 4. Elsevier.

Bagliano, Fabio-Cesare, \& Bertola, Giuseppe. 2004. Models for Dynamic Macroeconomics. Oxford University Press.

Bergin, Paul R., Feenstra, Robert C., \& Hanson, Gordon H. 2009. Offshoring and Volatility: Evidence from Mexico's Maquiladora Industry. American Economic Review, 99(4), 1664-71.

Bergin, Paul R., Feenstra, Robert C., \& Hanson, Gordon H. 2011. Volatility due to offshoring: Theory and evidence. Journal of International Economics, 85(2), $163-173$.

Cuñat, Alejandro, \& Melitz, Marc J. 2010. A many-country, many-good model of labor market rigidities as a source of comparative advantage. Journal of the European Economic Association, 8(2-3), 434-441.

Cuñat, Alejandro, \& Melitz, Marc J. 2012. Volatiliy, labor market flexibility, and the pattern of comparative advantage. Journal of the European Economic Association, 10(2), 225-254.

Dixit, Avinash K, \& Stiglitz, Joseph E. 1977. Monopolistic Competition and Optimum Product Diversity. American Economic Review, 67(3), 297-308.

Dornbusch, Rudiger, Fischer, Stanley, \& Samuelson, Paul A. 1977. Comparative Advantage, Trade, and Payments in a Ricardian Model with a Continuum of Goods. American Economic Review, 67(5), 823-39.

Grossman, Gene M., \& Rossi-Hansberg, Esteban. 2008. Trading Tasks: A Simple Theory of Offshoring. American Economic Review, 98(5), 1978-1997.

Haltiwanger, John. 2011. Globalization and economic volatility. Pages 119 - 145 of: Bacchetta, Marc, \& Marion Jansen (eds), Making Globalization Socially Sustainable. , World Trade Organization/International Labor Organization.

Manyika, James, Lund, Susan, Auguste, Byron, \& Ramaswamy, Sreenivas. 2012. Help wanted: The future of work in advanced economies. McKinsey Global Institute. 
Melitz, Marc J. 2003. The Impact of Trade on Intra-Industry Reallocations and Aggregate Industry Productivity. Econometrica, 71(6), 1695-1725.

RodrIK, Dani. 1998. Why Do More Open Economies Have Bigger Governments? Journal of Political Economy, 106(5), pp. 997-1032.

Roza, Marja, den Bosch, Frans A.J. Van, \& Volberda, Henk W. 2011. Offshoring strategy: Motives, functions, locations, and governance modes of small, medium-sized and large firms. International Business Review, 20(3), 314 - 323. 


\section{Appendix}

\section{Proof of Proposition (2):}

We first note that a firm's productivity level enters expected profits in a multiplicative way through the term $\Theta$; see $(26)$. Hence, for $\theta^{*}$ to fall as $k$ increases, we must have that $\frac{\partial E\left(\tilde{\pi}^{l}(\theta, Q)\right)}{\partial k}$ is larger for $l=S$ or for $l=N$. In view of (30), this is true if and only if

$$
k^{\frac{\beta}{1-\beta}}\left[\left(\Omega_{g}^{S}\right)^{\frac{-\beta}{1-\beta}}-\left(\Omega_{g}^{N}\right)^{\frac{-\beta}{1-\beta}}\right]>\left(\Omega_{b}^{S}\right)^{\frac{-\beta}{1-\beta}}-\left(\Omega_{b}^{N}\right)^{\frac{-\beta}{1-\beta}}
$$

It is straightforward to show that this implies

$$
k>\left(\frac{w^{N}+\gamma^{N}}{w^{N}-\gamma^{N}}\right)^{\eta}\left(\frac{\left(w^{S}-\gamma^{S}\right)^{\frac{-(1-\eta) \beta}{1-\beta}}-\left(w^{N}-\gamma^{N}\right)^{\frac{-(1-\eta) \beta}{1-\beta}}}{\left(w^{S}+\gamma^{S}\right)^{\frac{-(1-\eta) \beta}{1-\beta}}-\left(w^{N}+\gamma^{N}\right)^{\frac{-(1-\eta) \beta}{1-\beta}}}\right)^{\frac{1-\beta}{\beta}}
$$

Condition (i) of the proposition (positive hiring and firing) implies (31). Combining this with (A.2), we obtain

$$
\begin{aligned}
&\left(\frac{w^{l}+\gamma^{l}}{w^{l}-\gamma^{l}}\right)^{1-\eta} \geq\left(\frac{\left(w^{S}-\gamma^{S}\right)^{\frac{-(1-\eta) \beta}{1-\beta}}-\left(w^{N}-\gamma^{N}\right)^{\frac{-(1-\eta) \beta}{1-\beta}}}{\left(w^{S}+\gamma^{S}\right)^{\frac{-(1-\eta) \beta}{1-\beta}}-\left(w^{N}+\gamma^{N}\right)^{\frac{-(1-\eta) \beta}{1-\beta}}}\right)^{\frac{1-\beta}{\beta}} \\
&\left(\frac{w^{l}+\gamma^{l}}{w^{l}-\gamma^{l}}\right)^{\alpha} \geq \frac{\left(w^{S}-\gamma^{S}\right)^{-\alpha}-\left(w^{N}-\gamma^{N}\right)^{-\alpha}}{\left(w^{S}+\gamma^{S}\right)^{-\alpha}-\left(w^{N}+\gamma^{N}\right)^{-\alpha}}, \text { where } \alpha:=\frac{(1-\eta) \beta}{1-\beta}
\end{aligned}
$$

Assuming that $w^{N}+\gamma^{N}>w^{S}+\gamma^{S}$ allows us to multiply out, and setting $l=N$ we obtain $\left(w^{N}+\gamma^{N}\right)^{\alpha}\left[\left(w^{S}+\gamma^{S}\right)^{-\alpha}-\left(w^{N}+\gamma^{N}\right)^{-\alpha}\right] \geq\left(w^{N}-\gamma^{N}\right)^{\alpha}\left[\left(w^{S}-\gamma^{S}\right)^{-\alpha}-\left(w^{N}-\gamma^{N}\right)^{-\alpha}\right]$, which may be rewritten as

$$
\left(\frac{w^{N}+\gamma^{N}}{w^{S}+\gamma^{S}}\right)^{\alpha}-1 \geq\left(\frac{w^{N}-\gamma^{N}}{w^{S}-\gamma^{S}}\right)^{\alpha}-1
$$

Multiplying out we finally get condition (ii) of the proposition. Repeating the entire procedure for $l=S$, we find out that the exact same condition (ii) obtains.

But will $w^{N}+\gamma^{N}>w^{S}+\gamma^{S}$ be satisfied, as assumed in order to obtain (A.5)? In the final step of our proof we now demonstrate that this condition is logically equivalent to the condition that some firms engage in offshoring to start with, provided that condition (ii) of the propo- 
sition holds: $w^{S} / \gamma^{S}>w^{N} / \gamma^{N}$. This can be rewritten as $\left(w^{S}-\gamma^{S}\right) / \gamma^{S}>\left(w^{N}-\gamma^{N}\right) / \gamma^{N}$. Remembering that $w^{N}>\gamma^{N}$ as well as $w^{S}<\gamma^{N},{ }^{15}$ we may divide by $w^{N}-\gamma^{N}$, to obtain

$$
\frac{w^{S}-\gamma^{S}}{w^{N}-\gamma^{N}}>\frac{\gamma^{S}}{\gamma^{N}}
$$

Now, for offshoring to be attractive for at least some firms, we must have

$$
\begin{aligned}
w^{S}+\gamma^{S} & <w^{N}+\gamma^{N} \\
\text { or } \quad w^{S}-\gamma^{S} & <w^{N}-\gamma^{N}
\end{aligned}
$$

It is immediately obvious from (26) that offshoring will never be profitable, whatever a firm's productivity, if both of these conditions are violated at the same time. We now face two logical possibilities.

A) $\gamma^{S}>\gamma^{N}$ : Inequality (A.6), which follows from condition (ii) of the proposition, then implies $w^{S}-\gamma^{S}>w^{N}-\gamma^{N}$, which violates (A.8). But this may be rewritten as $w^{S}+\gamma^{S}>$ $w^{N}+\gamma^{S}+\left(\gamma^{S}-\gamma^{N}\right)$, and it is easily seen that that this implies condition (A.7) is violated as well. Thus, offshoring by at least some firms requires $\gamma^{N} \geq \gamma^{S}$.

B) $\gamma^{S} \leq \gamma^{N}$ : In this case, condition (A.8) implies condition (A.7), which becomes obvious from writing (A.8) as $w^{N}+\gamma^{N}>w^{S}+\gamma^{N}+\left(\gamma^{N}-\gamma^{S}\right)$. In other words, condition (A.8) in this case is the stronger of the two conditions (A.7) and (A.8).

All of this implies that we are left with (A.7), which is behind (A.5), as a necessary condition that offshoring takes place by at least some firms, given that North features a relatively inflexible labor market as specified in condition (ii) of the proposition. This completes the proof.

\footnotetext{
${ }^{15}$ We have argued at the outset that these conditions are utterly plausible. Violation of these conditions would imply that the marginal productivity of workers in the bad state would have to be negative.
} 